\title{
Ectopic release of GHRH and ACTH from an adenoid cystic carcinoma resulting in acromegaly and complicated by pituitary infarction
}

\author{
H.J. Southgate, G.P.R. Archbold, M.E. El-Sayed, ${ }^{1}$ J. Wright and V. Marks \\ Department of Clinical Biochemistry and ${ }^{1}$ Department of Radiotherapy, St. Luke's Hospital, Guildford, Surrey
}

\begin{abstract}
Summary: A 23 year old man presented with a tumour mass in the lung. Subsequent investigation showed ectopic secretion of adrenocorticotrophic hormone (ACTH) and growth hormone releasing hormone (GHRH) from an adenoid cystic carcinoma. The patient progressed to show the clinical effects of long term exposure to high blood levels of both growth hormone and cortisol. The case was complicated by pituitary infarction. The very high blood levels of ACTH, growth hormone (GH) and GHRH proved resistant to treatment with the somatostatin analogue, SMS 201-995, and a possible side effect of the drug is reported. To our knowledge this is the first reported case of ectopic hormone secretion by an adenoid cystic carcinoma.
\end{abstract}

\section{Introduction}

Acromegaly due to ectopic production of growth hormone releasing hormone (GHRH) has been described in association with a variety of tumours including carcinoid and pancreatic islet cell tumours. ${ }^{1,2,3,4}$ More than one ectopic hormone may be present in the tumour; in one reported case of metastatic carcinoid presenting clinically with acromegaly, gigantism and Cushing's syndrome, ${ }^{1}$ for example, both growth hormone $(\mathrm{GH})$ and GHRH were identified in the tumour. However, the presence of immunoreactive hormone in tumour tissue is not necessarily synonymous with ectopic hormone secretion; in one case of metastatic carcinoid, growth hormone was present in the tumour but no arteriovenous gradient was demonstrated across it. $^{5}$ We report a case of ectopic secretion of GHRH and adrenocorticotrophic hormone (ACTH) from an adenoid cystic carcinoma with failure to respond to the somatostatin analogue SMS-201-995 (Sandoz). The case was further complicated by pituitary infarction. To our knowledge this is the first reported case of ectopic secretion by adenoid cystic carcinoma.

Correspondence: H.J. Southgate B.Sc., M.R.C.P.(UK), M.R.C.Path.

Accepted: 7 August 1987

\section{Case report}

A 23 year old Caucasian man with no previous relevant medical history presented in June 1981 with pain in the right side of the chest and breathlessness. Chest X-ray showed a shadow in the right lung which was thought to have features of a dermatoteratoma. The patient refused further investigation, returning two years later in June 1983 complaining of a lump in the right side of the neck which had been present for some 8 months. Biopsy of the neck lump showed an adenoid cystic carcinoma which was presumed to be metastatic from the lung primary. Computed tomographic (CT) scan showed a large tumour mass in the right lung, and at thoracotomy an extensive nonresectable mediastinal mass was found. Treatment was commenced with radiotherapy to the chest and right side of the neck. In October 1983 the patient was admitted to St. Luke's Hospital, Guildford for chemotherapy. The patient was started on the Price-Hill chemotherapy regime (intermittent courses of vincristine, bleomycin, methotrexate and 5 fluoro-uracil). On admission, features of acromegaly were noted but no specific investigations were performed. The patient received seven cycles of chemotherapy finishing May 1984.

In July 1984 the patient was re-admitted complaining of thirst, polyuria, lethargy, unsteadiness of gait and bilateral swelling of both legs from foot to mid-calf. On examination, acne

(C) The Fellowship of Postgraduate Medicine, 1988 
vulgaris, bilateral exophthalmos and skin pigmentation were noted. Marked proximal muscle wasting was present in all four limbs. The strong clinical features of acromegaly were supported by radiological measurement.

Some initial biochemical investigations are shown in Table I. Plasma cortisol levels which were high with no diurnal variation and no response to either low dose $(2 \mathrm{mg}$ overnight) or high dose ( $2 \mathrm{mg}$ four times daily for 4 days) dexamethasone. Standard luteinising hormone releasing hormone (LHRH) and thyrotrophin releasing hormone (TRH) tests were performed; the results are shown in Table II. Basal testosterone was low and there was an exaggerated luteinising hormone (LH) response to LHRH. Although prolactin levels were markedly raised they subsequently fluctuated between 320 and $460 \mathrm{~m} \mathrm{U} / 1$ during a 6 hour saline infusion. Plasma $\mathrm{GH}$ levels - which were lower than on previous

Table I Selected results obtained prior to treatment and pituitary infarction

\begin{tabular}{ll}
\hline Random blood glucose & $29.4 \mathrm{mmol} / 1$ \\
Plasma albumin & $32 \mathrm{~g} / \mathrm{l}$ \\
Random plasma GH & $44 \mathrm{mU} / 1$ \\
Plasma IGF-1 & $4.16 \mathrm{U} / 1$ \\
$\quad$ (insulin like growth factor I) & normal range \\
& $0.4-2)$ \\
Random plasma cortisol & $1016 \mathrm{nmol} / 1$ \\
Random plasma C-peptide & $6.7 \mu \mathrm{g} / 1$ \\
Insulin antibodies & none detected \\
Plasma total thyroxine & $101 \mathrm{nmol} / 1$ \\
Plasma testosterone & $6 \mathrm{nmol} / 1$ \\
Urinary free cortisol & grossly elevated \\
Urinary VMA excretion & normal \\
$\quad$ (vanillylmandelic acid) & normal \\
Urinary 5HIAA excretion & \\
5 hydroxy indole acetic acid) & $300 \mu \mathrm{g} / 1$ \\
Plasma ACTH & $(\mathrm{normal}$ range \\
& $20-80)$ \\
Plasma GHRH & $45,000 \mathrm{ng} / 1$ \\
& $(\mathrm{normal}$ range \\
& $10-60)$ \\
\hline
\end{tabular}

occasions when they had been measured - rose in response to TRH/LHRH. Plasma thyroxine levels and the thyroid stimulating hormone (TSH) response to TRH were normal.

Hyperglycaemia persisted and the patient's diabetes which, in view of the high basal C-peptide levels appeared to be due to insulin resistance rather than to pancreatic failure, was treated with subcutaneous insulin 68 units twice daily initially, rising rapidly to 68 units four times a day. The oedema improved with diuretic therapy.

The patient was discharged home requiring 272 units of insulin daily to control his diabetes. He was readmitted the following day as an emergency complaining of severe frontal headaches and vomiting. He had marked photophobia and the history obtained from relatives suggested that he had also fitted. The fundi were normal. He recovered rapidly over 48 hours. A CT scan of the brain revealed a large sella turcica and several cerebral metastases. His symptoms were initially attributed to metastases and, despite hypercortisolaemia, he was treated with a high dose of oral dexamethasone $(2 \mathrm{mg}$ q.d.s.). Irradiation to the whole brain was given over 10 days to a total dose of $300 \mathrm{c} \mathrm{GY}$.

Although a single dose of the somatostatin analogue SMS 201-995 (Sandoz UK) $50 \mu \mathrm{g}$ subcutaneously had no acute effect on circulating levels of glucose, insulin, C-peptide, ACTH or cortisol, treatment was commenced at a subcutaneous dose of $50 \mu \mathrm{g}$ b.d. on 30 August 1984 . This produced no significant change in the clinical condition, plasma growth hormone, cortisol, blood glucose levels, or insulin requirements.

After 10 days acute copious diarrhoea developed. Insulin requirements fell dramatically and treatment with SMS 201-995 was stopped after which the diarrhoea gradually settled. Biochemical evidence now showed that the patient had suffered pituitary infarction, most likely during his previous acute admission. The episode of diarrhoea is unexplained but may have been due to the SMS 201-995.

Table II TRH/LHRH stimulation test

\begin{tabular}{|c|c|c|c|c|c|c|c|}
\hline & \multicolumn{7}{|c|}{ Plasma } \\
\hline & $\begin{array}{l}L H \\
I U / l\end{array}$ & $\begin{array}{l}F S H \\
I U / l\end{array}$ & $\begin{array}{c}T S H \\
m U / l\end{array}$ & $\begin{array}{c}\text { T4 } \\
n m o l / l\end{array}$ & $\begin{array}{c}G H \\
m U / l\end{array}$ & $\begin{array}{c}\text { Cortisol } \\
n m o l / l\end{array}$ & $\begin{array}{l}\text { Prolactin } \\
\qquad m U / l\end{array}$ \\
\hline Basal & 1 & 1 & 2.2 & 87.0 & 6.2 & 2058 & 2511 \\
\hline \multicolumn{8}{|c|}{$100 \mu \mathrm{g} \mathrm{LHRH}$ and $200 \mu \mathrm{g}$ TRH intravenously } \\
\hline $20 \mathrm{~min}$ & - & - & 14.3 & - & 27.1 & - & 1538 \\
\hline $30 \mathrm{~min}$ & 50 & 9 & - & - & - & - & 1014 \\
\hline $60 \mathrm{~min}$ & 27 & 4 & 10 & - & 11.2 & - & 473 \\
\hline
\end{tabular}


Pituitary function tests were performed on 1 October 1984. Basal TSH, LH, follicle stimulating hormone (FSH) and growth hormone were below the level of detection and showed no response to TRH and LHRH. Both total thyroxine $(34 \mathrm{nmol} / \mathrm{l})$ and 'free' thyroxine $(4.0 \mathrm{pmol} / \mathrm{l})$ were low but plasma cortisol, ACTH and GHRH levels remained high. Over the 6 months period following the presumed pituitary infarction, plasma insulin-like growth factor I (IGF-1) levels fell from 5.6 to $0.2 \mathrm{IU} / 1$ and prolactin levels fell to less than $50 \mathrm{mU} / 1$.

Pre-infarction plasma levels of gastrin, vasoactive intestinal polypeptide (VIP), glucagon, calcitonin, somatostatin and bombesin were normal at all times. Corticotrophin releasing factor (CRF) was undetectable in plasma both before and after pituitary infarction.

Immunoperoxidase staining of the tumour biopsy showed both ACTH and GHRH. No immunochemical CRF, GH or 5 hydroxytryptamine (5HT) was demonstrated. After further courses of chemotherapy and radiotherapy the patient gradually deteriorated and died some 9 months after the events described. A post-mortem examination was not obtained.

\section{Discussion}

This patient demonstrates ectopic production of both GHRH and ACTH by an adenoid cystic carcinoma. These tumours arise in the bronchus, trachea, breast or salivary gland and have a characteristic histological appearance. ${ }^{6}$ They have not previously been known to be associated with ectopic GHRH or ACTH production.

\section{References}

1. Frohman, L.A., Szabo, M., Berelowitz, M. \& Stachura, M.E. Partial purification and characterisation of a peptide with growth-hormone releasing activity from extrapituitary tumours in patients with acromegaly. J Clin Invest 1980, 65: 43-54.

2. Thorner, M.D., Perryman, R.L., Cronin, M.J. et al. Somatotroph hyperplasia: Successful treatment of acromegaly by removal of pancreatic islet cell tumours secreting a growth hormone releasing factor. $J$ Clin Invest 1982, 70: 965-977.

3. Guillemin, R., Brazeau, P., Bohlen, P. et al. Growth hormone releasing factor from a human pancreatic tumour that caused acromegaly. Science 1982, 218: 585-587.
Although arterio-venous differences across the tumour were not measured the evidence for ectopic production is good: (i) the failure of plasma ACTH and cortisol levels to respond to high dose dexamethasone; ${ }^{7}$ (ii) the persistence, following pituitary infarction of high plasma cortisol and ACTH levels; and (iii) the immunocytochemical demonstration of ACTH in the tumour.

Similarly, the presence of grossly elevated levels of GHRH in peripheral venous blood, with a fall in the high levels of growth hormone and IGF-1 but not GHRH, following pituitary infarction, together with the large amounts of GHRH demonstrated immunocytochemically in the tumour tissue, point to ectopic secretion of GHRH.

The somatostatin analogue, SMS 201-995, failed to suppress the elevated levels of $\mathrm{GH}$, insulin, glucose, GHRH or ACTH which contrasts with the findings in regular acromegaly where somatostatin and its analogues consistently lower basal $\mathrm{GH}^{8-12}$ and insulin levels ${ }^{13}$ and block the response to exogenous GHRH. ${ }^{8-12}$

The acute onset diarrhoea may have been a side effect of the drug but the case was complicated by pituitary infarction. Pancreatic steatorrhoea has been reported ${ }^{17}$ in patients receiving long term therapy with a higher dose of SMS 201-995.

The findings of a rise in plasma $\mathrm{GH}$ in response to TRH is in accord with the findings of Schulte ${ }^{14}$ in another patient with a GHRH-producing tumour. Our patient also had insulin-dependent diabetes mellitus - itself a cause of $\mathrm{GH}$ responsiveness to TRH. ${ }^{15}$ The reason for the GH response to TRH is not clear; it has been suggested that somatotroph hyperplasia secondary to hyperstimulation by GHRH permits TRH to become a secretagogue for $\mathrm{GH}^{16}$ but this must still be considered conjectural.
4. Rivier, J., Speiss, J., Thorner, M. \& Vale, W. Characterisation of a growth hormone releasing factor from a human pancreatic islet cell tumour. Nature 1982, 300: 276-278.

5. Dabek, J.T. Bronchial carcinoid tumour with acromegaly in two patients. J Clin Endocrinol Metab 1974, 38: 329-333.

6. Carter, D. \& Eggleston, J.C. Tumours of the Lower Respiratory Tract. Armed Forces Inst of Pathol 1979, Washington D.C. 20306: 199-203.

7. Liddle, G.W. Test of pituitary-adrenal suppressibility in the diagnosis of Cushing's syndrome. $J$ Clin Endocrinol Metab 1960, 20: 1529-1560. 
8. Pieters, G.F.F.M., Smals, A.E.M., Hermus, A.R.M.M. et al. Growth hormone responsiveness to human pancreatic growth hormone releasing hormone in acromegaly: Modulatory effects of basal hormone levels and of concomitant somatostatin administration. Clin Endocrinol 1984, 21: 701-707.

9. Lamberts, S.W.J., Verleun, T. \& Oosterom, R. The interrelationship between the effects of somatostatin and human pancreatic growth hormone releasing factor on growth hormone release by cultured pituitary tumour cells from patients with acromegaly. $J$ Clin Endocrinol Metab 1984, 58: 250-254.

10. Besser, G.M., Mortimer, C.H., Carr, D. et al. Growth hormone release inhibiting hormone in acromegaly. $\mathrm{Br}$ Med J 1974, 1: 352.

11. Yen, S.C.C., Siler, T.M. \& Devane, G.W. Effects of somatostatin in patients with acromegaly. $N$ Engl $J$ Med 1974, 290: 935.

12. Oppizzi, G., Botalla, L., Verde, G. et al. Homogeneity in growth hormone lowering effect of dopamine and somatostatin in acromegaly. J Clin Endocrinol Metab 1980, 51: 616-619.
13. Lamberts, S.W.J., Oosterom, R., Neufeld, M. \& DelPozo, E. The somatostatin analogue SMS 201-995 induces long acting inhibition of growth hormone secretion without hypersecretion in acromegaloid patients. J Clin Endocrinol Metab 1985, 60: 1161-1165.

14. Schulte, H.M., Benker, G., Windeck, R. et al. Failure to respond to growth hormone releasing hormone in acromegaly due to a GHRH secreting pancreatic tumour: dynamics of multiple endocrine testing. $J$ Clin Endocrinol Metab 1985, 61: 585-587.

15. Ceda, G.P., Speroni, G., Dall'Aglio, E. et al. Non specific growth hormone responses to thyrotropin releasing hormone in insulin dependent diabetes. $J$ Clin Endocrinol Metab 1983, 55: 170.

16. Borges, J.L.C., Uskavitch, D.R., Kaiser, D.L. et al. Human pancreatic growth hormone releasing factor (1-40) allows stimulation of GH release by TRH. $J$ Endocrinol 1983, 113: 1519.

17. Kvols, L.K., Moertel, C.G., O'Connell, M.J. et al. Treatment of the malignant carcinoid syndrome. Evaluation of a long acting somatostatin analogue. $N$ Engl J Med 1986, 315: 663-666. 